\title{
Beyond resilience to thriving: Optimizing child wellbeing
}

\author{
Tracy R. Gleason · Darcia Narvaez
}

\begin{abstract}
Research in child wellbeing often assesses the effects of particular disadvantages or focuses on children's resilience in adverse circumstances. In contrast, considering developmental optimization in early childhood, and what is necessary to foster it, informs the study of child wellbeing in the socioemotional domain. In the program of research reviewed here, we consider the kinds of early experiences that promote wellbeing, defined as optimal physiological and emotional regulation that enables a flexible sociomoral orientation to others. This work suggests that practices consistent with the evolved developmental niche (EDN), or the developmental system that likely characterized human caregiving over the course of evolution, facilitate development of the physiological and psychological systems of regulation that enable optimal wellbeing in the domain of sociomoral functioning. Aspects of EDN-consistent care provide a cohesive environmental context for development, but different facets of such care correspond to different outcomes related to socioemotional development. Overall, parental positive attitudes toward and provision of EDN-consistent care are associated with an orientation toward others that is prosocial, flexible, and engaged. These findings have emerged in samples in the US, Europe, and China, and suggest that the EDN might provide a useful framework for conceptualizing developmental optimization, for consideration of the important facets of early childhood care and education, and for fostering child wellbeing.
\end{abstract}

Keywords: wellbeing, early childhood, Evolved Developmental Niche, parenting, evolution, child development

\section{Introduction}

Historically, research into child wellbeing has had "an oddly pathogenic approach" (Amerijckx \& Humblet, 2014, p. 404), focusing on health, family, social, and economic problems (e.g., obesity, divorce, abuse, poverty) and considering wellbeing as a lack of such problems. Other researchers have pointed to children's capacity to overcome early or structural adversity to reach positive cognitive and social outcomes, such as absence of psychopathology and competence with peers or schooling (e.g., Masten, Best, \& Garmezy, 1990). While this research has documented many children's remarkable resilience, positive outcomes are not synonymous with wellbeing. Moreover, generalizing from experiences of resilient children encourages a perspective on wellbeing that suggests that treatment of young children is minimally influential on developmental outcomes (e.g., Lancy, 2015). 
Neurobiological and clinical studies suggest otherwise. For example, a lack of responsive care in the early years can lead to depressed affect (Karrass \& Walden, 2005) and a maladaptive stress response that lasts a lifetime, barring significant intervention (Gunnar, Larson, Hertsgaard, Harris, \& Broderson, 1992; Lupien, McEwen, Gunnar, \& Heim, 2009). Wellbeing thus involves more than survival and resilience. Specifically, the root of the term "health" is the same root for whole, hale and holy, meaning "complete, uninjured, sound" (Sanders, 2009, p. 50). If wellbeing includes health as a component, then traumatized individuals, even if resilient and recovering from adversity, are technically not exhibiting wellbeing. A comprehensive view of children's social and emotional wellbeing must include not just interventions for undoing the effects of early adversity, but provision of the contexts and supports that help children thrive. Our goal is thus to reconsider resilience and wellbeing from the perspective of these contexts to illustrate the components of early experience that might foster optimal development.

\section{Child Wellbeing}

\section{Defining Child Wellbeing}

Positive psychologists have defined wellbeing among adults as living "within an optimal range of human functioning, one that connotes goodness, generativity, growth, and resilience" (Fredrickson \& Losada, 2005, p. 678). By including goodness and generativity, this definition suggests that part of wellbeing is an outward focus on the condition of others, a sociomoral perspective of engagement, participation, and care. Likewise, the criteria for assessing wellbeing in childhood should include thriving in multiple dimensions, including the physical and social/emotional (Amerijckx \& Humblet, 2014). Wellbeing thus entails well-functioning emotional, psychological, and social capacities based in appropriate physiological and emotional regulation (Gleason \& Narvaez, 2014). These capacities allow for an orientation toward others that includes an ability to respond with warmth in situationally appropriate ways. This definition has two implications for moral development. First, rather than only reactive morality (e.g., obedience), child wellbeing includes proactive morality (e.g., voluntary helping), which involves empathy, cooperation, attention to the wellbeing of others, and sensitivity to how actions might influence others. Proactive morality is an indicator that a child has benefitted from a positive, supportive developmental context (e.g., Kochanska, 2002). Second, wellbeing in childhood and beyond is built on appropriate physiological, emotional, behavioral, and social regulation. Theoretically, well-functioning self-regulatory capacities equate to optimal functioning. Such capacities thus afford the ability to focus on others and be concerned for their wellbeing. This emphasis on social wellbeing distinguishes our definition from a notion of wellbeing that focuses on child survival, resilience, or minimally adequate care with no reference to the role of the self in society.

\section{Child Wellbeing and Self-Regulation}

Self-regulation is a fundamental goal of development. It has been studied in various domains and can be laid out chronologically over the course of maturation. First, physiological regulation emerges, including internal biological mechanisms such as breathing and digestion. These are 
functions a baby must learn to do independently of the mother's body. Additional physiological regulatory systems are established postnatally, such as the stress response and various endocrine systems (Carter \& Porges, 2013; Lupien et al., 2009). Emotion regulation develops over many years as the capacity to modify the intensity and duration of emotions (Calkins \& Hill, 2007; Thompson, 2011). With age and experience, the child develops attentional regulation, the capacity to maintain on-task focus (see Calkins \& Fox, 2002; Fogel, 1993; Posner \& Rothbart, 1998; Tucker, Derryberry, \& Luu, 2000). Lastly, behavior regulation includes impulse control, stopping and starting action, and other capacities reliant on executive functions (Goldberg, 2002). All of these forms of regulation are developed with the help of caregivers, who initially do much of the work of physical and psychological regulation but gradually withdraw their support as the child becomes able to self-regulate. In early life, the actual physical presence and mutually responsive relationships with caregivers foster the neurobiological foundations of self-regulation (Kochanska, 2002; Schore, 2003a, 2003b). As the child develops, regulatory approaches that depend upon cognition (e.g., verbal advice) can be used by caregivers to guide the child in monitoring and shaping behavior.

Neuroscience provides insight into how early experience might influence self-regulation. Specifically, human neonates are characterized by neurological immaturity. The majority of brain size and functioning is grown and shaped postnatally by early experiences, which in humans are largely social (Narvaez, Panksepp, Schore, \& Gleason, 2013). Consequently, human infants require an "external womb" experience, provided by caregivers, as they develop capacities to regulate temperature, the sleep/wake cycle, and arousal levels (Montagu, 1968; Moore et al., 2009; Spangler, Schieche, Ilg, Maier \& Ackerman, 1994). A child whose hormonal states are not kept in balance by sensitive caregiving during rapid brain growth in the early years shows permanent changes to neurobiological functioning (for reviews, see Lanius, Vermetten \& Pain, 2010). Thus, self-regulatory capacities come about in the context of social relationships as the child matures through multiple sensitive periods (Narvaez, Panksepp et al., 2013).

These studies suggest that the early years significantly influence lifelong capacities for self-regulation and the capacities upon which self-regulation relies, such as sociality and moral socialization. Given the role of self-regulation in children's (and later adults') ability to thriveincluding sociomoral engagement with others - we have been investigating the early experiences and developmental contexts associated with child wellbeing. The basis of this work rests in the fact that human infants, as neurologically-immature, social mammals, require the cooperation of adults to meet their innate needs. Indeed, sociality and cooperation are key adaptations that emerged over the course of evolution (Hrdy, 2009). As adults provide for the needs of infants and young children, they nurture the children's capacities for cooperation, biosocially constructing them through experience and fostering sociomoral wellbeing. This process occurs within our species-specific developmental system called the evolved developmental niche.

\section{Fostering Wellbeing in Early Childhood}


According to Developmental Systems Theory, a comprehensive evolutionary theory, humans inherit many things from their ancestors beyond genes, from culture to ecologies to a developmental system for raising the young (Oyama, 1985; Oyama, Griffiths \& Gray, 2001). This system is referred to as humanity's evolved developmental niche (EDN). Every animal species has an EDN for its young that corresponds to the maturational needs of offspring. Humans are no exception, and we adapted the social mammalian nest that emerged over 30 million years ago for our unique needs. The human EDN is particularly intensive due to the immaturity of our offspring at birth, which was necessitated by the smaller pelvis and narrower birth canal resulting from humanity's move to bipedalism. Full-term newborns look like fetuses of other animals until about 18 months of age (Trevathan, 2011). Although we cannot know for certain the early experiences and developmental contexts of our ancestors over the course of evolutionand likely they varied significantly-anthropologists have suggested that small-band huntergatherer communities, nomadic foragers, represent the type of society in which humanity spent 99\% of its genus history. Hewlett and Lamb (2005) summarized the experiences of young children in these societies:

[Y]oung children in foraging cultures are nursed frequently; held, touched, or kept near others almost constantly; frequently cared for by individuals other than their mothers (fathers and grandmothers, in particular) though seldom by older siblings; experience prompt responses to their fusses and cries; and enjoy multiage play groups in early childhood (p. 15).

In our work, we have focused on these experiences, particularly responsiveness, touch, social support/alloparenting (caregiving shared among multiple adults), and play. The characteristics of these practices in hunter-gatherer communities and research findings relating these practices to children's physiological and psychological health provide the basis for our hypotheses connecting children's early experiences to their social and emotional wellbeing, particularly in the sociomoral domain.

Responsiveness. In nomadic foraging societies, babies and young children spend most of their time in the arms of caregivers. Babies rarely cry, and when they do, adults respond immediately (Konner, 2005; Morelli, Ivey Henry \& Foerster, 2014). The baby's cry irritates adults and may have evolved to do so to elicit care and avoid alerting predators (Trevathan, 2011). The baby's needs, like breastfeeding or suckling, are met on request. Babies are kept calm and content through attentive care.

In attentive early care, the child and caregiver form a "relational communication system" in which optimal levels of physiological arousal and co-coordinated action are maintained (Evans \& Porter, 2009; Fogel, 2000; Fogel \& Branco, 1997). Extensive experience of synchrony and reparation of asynchrony facilitate the child's capacities for self-control and foster secure attachment (Feldman, Greenbaum, \& Yirmiya, 1999; Schore, 2013; Tronick, 2007). Responsive care is considered fundamental to the development of a secure attachment style (as opposed to an insecure or disorganized style) (Sroufe, 1996). Responsive care also shapes a healthy stress response (Lupien et al., 2009). Many capacities that develop in the first months and years, like 
the attachment system and vagus nerve function, are dependent on the postnatal time period for right hemisphere directed development of self-regulation and sociality (Schore, 2003a, 2003b; Schore \& Schore, 2008).

Touch. Ever since the work of Harry Harlow (1986) pointed to the importance of the physical presence of the mother, touch has been examined in various ways. Animal models indicate that caregiver touch has epigenetic effects during sensitive periods, affecting lifelong self-regulation (Meaney, 2001). Human studies indicate that infant massage promotes physiological regulation longitudinally (Feldman, Weller, Sirota, \& Eidelman, 2002) and health over the long term for premature infants (see Field, Diego, \& Hernandez-Reif, 2010, for a review). In infancy, caregiver touch and close presence at night are associated with healthy regulatory processes through endocrine modulation, reduction of stress hormones and proper vagal system functioning (Carter \& Porges, 2013; Field et al., 2010; McKenna et al., 1994).

Social Support/Alloparenting. In hunter-gatherer communities, mothers and infants receive nearly constant social support. Initially, mothers are steady companions of babies but with development, young children spend more than half the time with other responsive caregivers (Hewlett \& Lamb, 2005; Morelli et al., 2014). In fact, our species evolved to raise children through "cooperative breeding" (Hrdy, 2009), with mothers supported at birth, postnatally, and beyond. In the long term, mothers who feel socially supported have children with fewer behavior problems and greater social skills (McConnell, Breitkreuz, \& Savage, 2011). For the child, alloparenting has several known advantages, including providing opportunities for engaging in beneficial social interactions and the development of flexible social skills and social openness (Hrdy, 2009; Koverola et al., 2005). In studies of resilience in adverse conditions, nonparental adult relations are a protective factor for children of all ages (Masten et al., 1990). Multiple adult caregivers are correlated with more effective parenting, lowering the risk of social, emotional, and cognitive problems even into adulthood (Amato, 2005).

Play. Children in nomadic foraging communities spend most of their time in the natural world with multi-age playmates in self-directed social play. Engaging in such free play has multiple benefits (Flanders, Herman, \& Paquette, 2013; Gray, 2013; Pellegrini \& Pellegrini, 2013). In the roles and challenges they voluntarily take on, children practice impulse control and responding to the unexpected. In early childhood, free play allows children to imagine and explore different social roles and situations where they can learn from trial and error and invent new solutions, heightening their problem solving and creativity. Social pretend play provides a way to practice cooperation, negotiation, and compromise (Doyle \& Connolly, 1989; Howe, Petrakos, \& Rinaldi, 1998). Fantasy and rough-and-tumble play require intricate interactions with others and are correlated with emotion regulation in early to middle childhood (Lillard et al., 2013; Pellegrini \& Smith, 1998). In middle childhood, children learn self-assertion, sensitivity, sharing and consensual decision-making, as well as how to deal with social conflict. Children who experience more unsupervised social play tend to show more self-control, including less aggression. Experiments show that depriving children of play for short periods compromises attention and leads to longer and more intense engagement in play subsequently (Pellegrini \& Smith, 1998). Even in adolescence and adulthood, non-competitive play provides a forum for fostering cooperation among group members (Gray, 2014). 
By examining these components in relation to children's developmental outcomes, we have conducted a program of research exploring whether early experiences consistent with the EDN provide a developmental context that fosters children's sociomoral wellbeing. In general, our work has been guided by the hypothesis that developmental optimization is associated with EDN-consistent practices, and that wellbeing is a function of such optimal early experience. Theoretically, such early care provides the set of experiences that maximize physical, emotional, attentional, and behavioral regulation, providing the child with the neuropsychological resources for sociomoral engagement with others. Such engagement can be measured through the child's regulatory capacities (e.g., executive function, cooperation) and through maternal reports of typical behavior that translate into measures of the child's development of conscience.

Triune ethics meta-theory (Narvaez, 2008, 2014) describes how self-regulatory processes are integral to sociomoral functioning. These are represented in implicit social cognitive systems that are activated in social situations. When regulatory systems are less than optimal, stress response patterns can be activated in relational encounters (attack/oppose, withdraw, dissociate). When neurobiological systems are well constructed, with sociality nourished in early life, relationally attuned patterns are activated in social encounters (e.g., engagement, social imagination). Theoretically, these patterns become dispositional, providing the individual with a default response to moral situations that is either stressed and defensive or engaged and prosocial. In adult studies, these dispositions correlate in expected directions with measures of sociomoral capacities like empathy and perspective taking (e.g., Narvaez, 2018; Narvaez, Wang, \& Cheng, 2016).

\section{EDN-Consistent Care and Child Wellbeing}

Our approach to empirically testing child wellbeing has been guided by two theoretical ideas. First, we conceptualize early care consistent with the EDN as providing a nurturing environment that optimizes development and promotes wellbeing by cultivating healthy physiological and psychological systems. One way in which children's wellbeing is manifested through these systems is in their behavior, specifically through a) prosociality, b) an engaged and imaginative sociomoral orientation toward others, and c) absence of psychopathology. Second, while we expected that EDN-consistent care overall would promote positive outcomes and minimize negative outcomes, we also theorized that each component of EDN-consistent care, such as touch or responsiveness, might have differential associations with child outcomes. Much in the way that different vitamins and minerals support specific aspects of physiological functioning, various aspects of EDN-consistent care might have specific implications for particular child outcomes.

In an attempt to test these hypotheses (Gleason, Narvaez, Cheng, Wang, \& Brooks, 2016), we conducted a study in which we examined the extent to which the caregiving practices associated with the EDN constitute a holistic, nurturing environment. Specifically, we wondered whether mothers of preschoolers who held positive attitudes toward responsiveness would likewise be those mothers who endorsed caregiving that included copious positive touch, extensive play with peers, and alloparenting. This hypothesis was supported in our study, as all 
of these variables were highly correlated $(r s>.5, p s<.001)$. Confirmatory factor analysis also supported the idea of these components forming a latent construct of nurturing parenting, meaning that mothers who endorsed these views tended to see their own responsive care in a socio-environmental context that also included valuable contributions from peers through play, and from other adults through nurturing. This view of early development is consistent with work that moves beyond the mother-child relationship to recognize and acknowledge the role of other important individuals in the child's life, including peers. For example, extensive work relates sociomoral outcomes such as empathy and conscience to sensitive parenting and the emotional climate of the mother-child relationship (e.g., Kochanska, 2002), but additional research highlights the ways in which the peer group affects moral thinking and behavior, particularly later in childhood (e.g., Kruger, 1992; Walker, Hennig, \& Krettenauer, 2000).

We were also interested in the extent to which maternal endorsement of EDN-consistent care would be related to children's early psychosocial health and sociomoral development, hypothesizing that nurturing parenting would relate to children's sociomoral flourishing, a latent variable composed of happiness, social consideration, social attunement, social imagination, and empathy, measured via maternal report using validated scales. We also tested whether nurturing parenting attitudes would relate to ill-being, a latent variable comprised by maternal reports of validated measures of social withdrawal, depression, anxiety, and wellbeing (negatively), or antisocial behavior, which was made up of social opposition, social distrust, and misbehavior (all models controlled for income). All of these hypotheses were supported, meaning that sociomoral flourishing and psychological wellbeing were positively correlated with maternal endorsement of nurturing parenting. This connection is significant for two reasons. First, while parental warmth has long been associated with internalization of morality and avoidance of misbehavior (Hoffman, 1970), our measures included mothers' attitudes toward play and alloparenting in the conceptualization of nurturing parenting, not just aspects of warmth such as responsiveness and positive touch. Second, while attitudes do not always translate into behavior, the high consistency among the parenting attitudes measured raises their predictive validity for behavior (Holden \& Buck, 2002). The findings seem consistent with the idea that endorsement of EDN-consistent attitudes is connected with positive sociomoral and psychological outcomes, possibly through parental behaviors and/or the creation of a nurturing environment that fosters wellbeing.

We also explored the differential connections between components of the EDN and the various child outcomes related to wellbeing in a sample of Chinese mothers $(N=383)$ of preschool children (Narvaez, Wang et al., 2013). In this study, we queried mothers about both their attitudes and behaviors toward nurturing parenting, including the EDN components listed above as well as extensive breastfeeding, nearly constant touch, multiple adult caregivers (i.e., alloparenting), family cohesion, co-sleeping, playful interactions, and natural childbirth (Hewlett $\&$ Lamb, 2005). We looked at the effects of these practices on child outcomes related to sociomoral development: inhibitory control and self-regulation, empathy, and conscience development, including guilt after wrongdoing and concern for others. Much as in our other study, we found significant but differential positive relationships between many of our predictors and outcomes. 
The connections between parenting practices and outcomes highlighted the particular importance of responsiveness, play behavior, and touch, as these practices related most strongly to children's sociomoral outcomes (see Table 1).

Table 1

Regression Coefficient Estimates (and Effect Sizes) for EDN Variables by Child Outcomes

\begin{tabular}{|c|c|c|c|c|c|c|c|c|c|c|}
\hline \multirow{3}{*}{$\begin{array}{l}\text { EDN variables } \\
\text { Maternal } \\
\text { responsivity }\end{array}$} & \multicolumn{4}{|c|}{ Behavior regulation } & \multirow{2}{*}{\multicolumn{2}{|c|}{ Empathy }} & \multicolumn{4}{|c|}{ Conscience } \\
\hline & \multicolumn{2}{|c|}{ Inhibitory control } & \multicolumn{2}{|c|}{ Self-regulation } & & & \multicolumn{2}{|c|}{ Guilt } & \multicolumn{2}{|c|}{ Concern } \\
\hline & $.266^{* * *}$ & $(.038)$ & .033 & $(.001)$ & $.362^{* * *}$ & $(.082)$ & $.156^{*}$ & $(.014)$ & $.423^{* * *}$ & $(.071)$ \\
\hline $\begin{array}{l}\text { Breastfeeding } \\
\text { length (mos.) }\end{array}$ & $.015^{*}$ & $(.023)$ & .005 & $(.017)$ & -.008 & $(.012)$ & $.016^{*}$ & $(.017)$ & $.019^{*}$ & $(.021)$ \\
\hline $\begin{array}{l}\text { Touch behavior } \\
\text { in infancy }\end{array}$ & $.180^{* *}$ & $(.021)$ & $.126^{*}$ & $(.017)$ & $.290^{* * *}$ & $(.065)$ & .033 & (.609) & $.195^{*}$ & $(.018)$ \\
\hline $\begin{array}{l}\text { Touch behavior } \\
\text { now }\end{array}$ & $.326^{* * *}$ & $(.051)$ & $.150^{*}$ & $(.017)$ & $.293^{* * *}$ & $(.047)$ & .130 & $(.009)$ & $.420^{* * *}$ & $(.061)$ \\
\hline $\begin{array}{l}\text { Family cohesion } \\
\text { attitudes }\end{array}$ & $.256^{* * *}$ & $(.046)$ & .060 & $(.004)$ & $.224^{* * *}$ & $(.040)$ & $.132^{*}$ & $(.011)$ & $.315^{* * *}$ & $(.052)$ \\
\hline $\begin{array}{l}\text { Play with } \\
\text { mother }\end{array}$ & $.255^{* * *}$ & (.033) & $.163^{* * *}$ & $(.021)$ & $.225^{* *}$ & $(.029)$ & .072 & $(.001)$ & $.246^{* *}$ & $(.022)$ \\
\hline $\begin{array}{l}\text { Play with other } \\
\text { adults }\end{array}$ & $.113^{*}$ & $(.016)$ & $.112^{* *}$ & $(.021)$ & $.116^{*}$ & $(.021)$ & .080 & $(.006)$ & $.127^{*}$ & $(.016)$ \\
\hline
\end{tabular}

Note: $\mathrm{EDN}$ = Evolved Developmental Niche. Mos. = months. All analyses were run using maternal education and household income as covariates. Effect sizes were computed using Cohen's (1988) method for variables and covariates. By convention, effect sizes of .02, .15, and .35 are small, medium, and large, respectively. Excerpted from "The evolved developmental niche and child sociomoral outcomes in Chinese 3year-olds," by D. Narvaez, L. Wang, T. Gleason, Y. Cheng, J. Lefever, and L. Deng, 2013, European Journal of Developmental Psychology, 10, p. 116.

${ }^{*} p<.05 .{ }^{* *} p<.01 .{ }^{* * *} p<.001$.

However, singular links between practices and child outcomes suggested significant complexity in the system. For example, play and positive attitudes toward family cohesion related to children's empathy, but breastfeeding did not. Breastfeeding did, however, correlate with aspects of sociomoral development that involved self-control, specifically, our measures of inhibitory control and conscience. These links, which remained small but significant even after controlling for maternal responsivity, fit with a theoretical model that connects early parenting with the organization of physiological and psychological systems that support children's moral functioning. Certainly, the extensive work on children's resilience (e.g., Masten et al., 1990) argues against the idea that missing one of the EDN components, such as positive touch or breastfeeding, will compromise a child's outcomes, but the findings of this study suggest that optimal child wellbeing might be a function of the combined facets of EDN-consistent care.

The general consistency that we found in our studies of maternal attitudes in the US and attitudes and behavior in China prompted two developments: a) we created a measure that could function as a checklist of the child's recent experience of EDN-consistent care in the past week, 
and $b$ ) we further explored the nature of the relationships between the EDN and sociomoral outcomes in multiple cultures (Narvaez et al., 2019). We created the Evolved Developmental Niche Provision Report (EDNPR), a 6-item checklist of EDN-consistent parenting practices adapted from an adult measure of childhood experiences of EDN-consistent care. Items addressed provision of positive/negative touch, indoor/outdoor free play, and family togetherness inside/outside the home. This composite was connected to parent reports of three latent variables: preschool children's moral socialization (internalized conduct, inhibitory control, concern after wrongdoing, and empathy), sociality (social attunement, social enjoyment, and social imagination, as well as consideration, thriving, and happiness), and social maladaptation (social opposition, distrust, and withdrawal, along with anxiety, depression, and misbehavior), each of which was assessed using validated maternal report measures. We controlled for parent age, education, income, child gender, and parental responsiveness. We tested these structural equation models in the US $(n=574)$, China $(n=382)$, and Switzerland $(n=$ 96).

Although the results from the Swiss sample were somewhat equivocal owing to the small sample size, the general pattern of results was consistent with our other studies. Scores on the EDNPR correlated with sociality, in particular, in all three samples (US: $\mathrm{b}=.22, p<.001$; China: $\mathrm{b}$ $=.13, p=.03$; Swiss: $\mathrm{b}=.51, p<.001)$ and above and beyond the effects of the other covariates, including responsiveness. These findings are consistent with the notion that provision of EDNconsistent care provides a social environment in which children develop a positive orientation toward others, characterized by enjoyment of social interaction, pleasure in the company of others, and capacities to get along. This emotional climate is also consistent with that described by anthropologists in nomadic foraging communities (Hewlett \& Lamb, 2005; Konner, 2005). Scores on the EDNPR also related to moral socialization, but only in the US and China and with small effect sizes (US: $b=.17, p=.005$; China: $b=.14, p=.02$; Swiss: $b=.20, p=.11$ ). Our interpretation of these results is that EDN-consistent care and moral socialization are related, but pale in comparison to connections to responsive parenting. As moral socialization relates to selfregulatory processes and the development of empathy, these child outcomes may correlate more highly with the sensitivity and responsivity that parents demonstrate in their interactions with their children, rather than the EDN-consistent components of touch, play, and family togetherness measured by the EDNPR. Similarly, relations between EDNPR scores and social maladaptation were only significant in the US sample (US: $b=-.11, p=.02$; China: $b=-.02, p=.80$; Swiss: $\mathrm{b}=.01, p=.99$ ), suggesting that the absence of the elements of EDN-consistent care measured by the EDNPR is not necessarily related to dysregulation. But as noted, EDNPR did connect to sociality, an aspect of optimal development, in all three samples. EDN-consistent care might thus help explain the difference between adequate care (i.e., care that reduces psychopathology, misbehavior, and a protectionist stance toward social interaction) and actual thriving. As our definition of wellbeing moves beyond simply the absence of maladaptation, EDN-consistent care is thus theoretically an important part of developmental optimization and thus of wellbeing itself.

In a separate study (Narvaez, Gleason, et al., 2013), we used an existing longitudinal data set of families at risk for neglect $(N=682)$ to investigate whether maternal responsivity, 
breastfeeding initiation, touch, and maternal social support (as a proxy for alloparenting) were tied over time to a relevant set of child outcomes available in the data set, including children's behavior problems, measures of cognitive development, and prosociality (cooperation and social engagement). This data set provided an important step forward for our work, as it afforded analysis of child outcomes based not just on parental report, but on observations and measures of children's behavior. Data were used from interviews that took place during the mothers' last trimester of pregnancy and when their infants were 4, 6, 8, 12, 18, 24, 30, and 36 months old, and included both maternal report and observations of mother-child interaction and of the home. Children were also tested using standardized IQ and language tests at 24 and 36 months. We hypothesized that maternal responsiveness would have the greatest implications for all child outcomes given its centrality to mother-child dyadic functioning, and that these associations would emerge early in infancy. We expected breastfeeding initiation to predict better cognitive development and lower behavior problems, touch (as a buffer against stress) to support prosociality and lower behavior problems, and maternal social support to relate positively to both prosociality and cognitive development as well as negatively to behavior problems. In our analyses, we controlled for maternal age/education and income-to-needs ratio.

The models we developed to describe this multivariate, longitudinal data set revealed patterns consistent with our theoretical framework and information on how relations between our variables changed over time (see Table 2). For example, children's prosociality was strongly predicted by early maternal responsivity, as well as by positive changes in responsivity over time. High early responsivity also predicted lower behavior problems in preschool and cognitive development at age two. Although cognitive development at age three was not predicted by early responsiveness, a greater increase in responsivity predicted cognitive scores at this age.

Because of the many associations between maternal responsivity and child outcomes in prior research we controlled for it as we looked at the other EDN-consistent caregiving behaviors. Many associations remained, lending support to the idea that each component of EDN-consistent care might contribute differentially to child wellbeing, either by affecting different outcomes or by affecting them at different times. For example, high rates of positive touch early in development predicted both higher cognitive ability and lower behavior problems in preschool. In contrast, initiation of breastfeeding predicted prosociality in toddlerhood (at 18 months) and fewer behavior problems at age two. Social support, as a proxy for alloparenting, positively predicted prosociality and cognitive ability in toddlerhood and negatively predicted behavior problems at age two. Overall, the findings of this study supported the conclusions that a) children's wellbeing might be best supported by the combined presence of EDN-consistent caregiving practices, and b) often EDN-consistent patterns are established early. However, the relations between predictors and outcomes varied over time, suggesting that the positive effects of some early practices might not be immediately apparent. 
Table 2

Model Results for Effects of EDN Variables on Child Outcomes

\begin{tabular}{|c|c|c|c|}
\hline EDN component & Child outcome & Coefficients & Model Fit \\
\hline \multicolumn{4}{|l|}{ Maternal responsivity } \\
\hline At 4 mos. & Prosociality 18 mos. & $.44^{*}$ & \multirow{3}{*}{$\begin{array}{l}\chi^{2}(26, N=583)=29.29, p=.30, \mathrm{CFI} \\
=.963, \mathrm{RMSEA}=.053\end{array}$} \\
\hline At 4 mos. & Prosociality 30 mos. & $.21^{*}$ & \\
\hline Change (4-30 mos.) & Prosociality 30 mos. & $.40^{*}$ & \\
\hline At 4 mos. & Behavior problems 24 mos. & $-.20^{*}$ & \multirow{3}{*}{$\begin{array}{l}\chi^{2}(26, N=583)=17.51, p=.89, \text { CFI } \\
=.986, \text { RMSEA }=.035\end{array}$} \\
\hline At 4 mos. & Behavior problems 36 mos. & $-.07^{*}$ & \\
\hline Change (4-30 mos.) & Behavior problems 36 mos. & -.04 & \\
\hline At 4 mos. & Cognitive ability 24 mos. & $.33^{*}$ & \multirow{3}{*}{$\begin{array}{l}\chi^{2}(47, N=583)=44.55, p=.53, \text { CFI } \\
=.966, \text { RMSEA }=.049\end{array}$} \\
\hline At 4 mos. & Cognitive ability 36 mos. & -.04 & \\
\hline Change (4-30 mos.) & Cognitive ability 36 mos. & $.16^{*}$ & \\
\hline \multirow[t]{2}{*}{$\begin{array}{l}\text { Breastfeedinga }(0= \\
\text { no, } 1=\text { yes })\end{array}$} & Prosociality 18 mos. & $.10^{*}$ & $\begin{array}{l}\chi^{2}(20, N=583)=26.84, p=.14, \text { CFI } \\
=.963, \text { RMSEA }=.059\end{array}$ \\
\hline & Behavior problems 24 mos. & $-.15^{*}$ & $\begin{array}{l}\chi^{2}(20, N=583)=14.59, p=.80, \text { CFI } \\
=.983, \text { RMSEA }=.039\end{array}$ \\
\hline \multicolumn{4}{|l|}{ Touch $^{\mathrm{a}}$} \\
\hline At 4 mos. & Behavior problems 24 mos. & -.03 & \multirow{3}{*}{$\begin{array}{l}\chi^{2}(59, N=583)=79.52, p=.04, \text { CFI } \\
=.933, \text { RMSEA }=.057\end{array}$} \\
\hline At 4 mos. & Behavior problems 36 mos. & $-.17^{*}$ & \\
\hline Change (4-30 mos.) & Behavior problems 36 mos. & -.03 & \\
\hline At 4 mos. & Cognitive ability 24 mos. & $-.11^{*}$ & \multirow{3}{*}{$\begin{array}{l}\chi^{2}(87, N=583)=109.24, p=.06, \mathrm{CFI} \\
=.933, \mathrm{RMSEA}=.056\end{array}$} \\
\hline At 4 mos. & Cognitive ability 36 mos. & $.23^{*}$ & \\
\hline Change (4-30 mos.) & Cognitive ability 36 mos. & -.06 & \\
\hline \multirow[t]{4}{*}{ Social supporta } & Prosociality 18 mos. & $.27^{*}$ & \multirow{2}{*}{$\begin{array}{l}\chi^{2}(41, N=583)=59.05, p=.03, \text { CFI } \\
=.934, \text { RMSEA }=.062\end{array}$} \\
\hline & Prosociality 30 mos. & $.11^{*}$ & \\
\hline & Behavior problems 24 mos. & $-.24^{*}$ & $\begin{array}{l}\chi^{2}(29, N=583)=20.80, p=.87, \text { CFI } \\
=.980, \text { RMSEA }=.037\end{array}$ \\
\hline & Cognitive ability 24 mos. & $.15^{*}$ & $\begin{array}{l}\chi^{2}(39, N=583)=33.10, p=.74, \text { CFI } \\
=.976, \text { RMSEA }=.040\end{array}$ \\
\hline
\end{tabular}

Note EDN $=$ Evolved Developmental Niche. Mos. = months. Coefficients are standardized. All results listed are controlling for demographic covariates (income/needs ratio and mother's age/education group). Adapted from "The evolved development niche: Longitudinal effects of caregiving practices on early childhood psychosocial development," by D. Narvaez, T. Gleason, L. Wang, J. Brooks, J. Burke Lefever, Y. Cheng, and the Centers for the Prevention of Child Neglect, 2013, Early Childhood Research Quarterly, 28, p. 766.

aResults are controlling for maternal responsivity in addition to demographic covariates. ${ }^{*} p<.05$. 
The idea that the components of EDN-consistent care contribute differentially to child outcomes prompted us to look more closely at relations between a few of those components, specifically touch (Narvaez et al., in press) and play (Gleason et al., 2019), and their relations to aspects of sociomoral development and wellbeing. We chose touch for several reasons, not the least of which is that, as described above, absence of touch is considered a stressor in mammals (Sapolsky, 2004), and because nurturing physical touch promotes healthy physiological development in social mammals, including humans (Field et al., 2010). Physiology, in turn, is related to wellbeing and psychosocial functioning (Feldman, Gordon, \& Zagoory-Sharon, 2011). We thus hypothesized that sociomoral wellbeing would be at least in part a function of early experiences of touch. Our examination of touch included three studies. In the first, we found that the attitudes toward touch of mothers of preschoolers $(N=156)$ were positively correlated with children's social thriving (i.e., an engaged sociomoral orientation and sociomoral capacities such as empathy; $b=.66, p<.01)$ and negatively correlated with antisocial behavior $(b=-.32, p<.01)$. Similarly, our longitudinal examination using the existing dataset of at-risk mothers demonstrated moderate to strong relationships between behavioral regulation at 18 months and concurrent positive touch $(r=.15, p=.03)$ and lack of negative touch $(r=.24, p<.001)$ and positive correlations between low corporal punishment and sociomoral outcomes, such as social engagement $(r=.22, p=.002)$ and cooperation $(r=.28, p<.001)$, at 30 months. Lastly, a study with adults $(N=607)$ revealed significant connections between retrospective reports of childhood touch and adult moral orientation (i.e., social engagement, opposition, and withdrawal), mediated by attachment security, mental health (anxiety and depression), and moral capacities (e.g., empathy). In short, across these disparate studies, more affectionate touch and less negative touch were positively associated with wellbeing and with development of moral capacities and an engaged moral orientation.

Like some of our earlier work, our examination of play included models that we tested in two samples, in the US and in China (Gleason et al., 2019). Our particular interest in play as affording wellbeing and sociomoral development arose from the myriad research connecting play to relevant social skills in early childhood, such as emotion regulation (Lindsey \& Colwell, 2013), delay of gratification (Cemore \& Herwig, 2005), and cooperation and sharing (Woolf, 2011). We reasoned that as arbiters of children's play, mothers' positive attitudes toward children's play and reports of children's play behavior might mediate the relation between mothers' memories of their own childhood play experiences and children's social thriving, moral socialization, and social maladaptation.

The results of our analyses suggested connections particularly between maternal history and children's social thriving in both samples, mediated by mothers' attitudes toward play and reports of their children's play behaviors. Similarly, mothers' attitudes mediated the relation between maternal history and children's moral socialization. Play attitudes and reports of play behavior, however, did not mediate between maternal history and children's social maladaptation. In other words, this component of the EDN seems to play a significant role in mediating mothers' childhood experiences and children's prosocial orientation, and to a weaker extent children's moral self-regulation. The fact that social thriving was predicted by maternal play attitudes and child play behavior suggests play's importance for optimal wellbeing. In 
contrast, the lack of mediation for social maladaptation emphasizes the role of EDN components other than play as contributors to children's physical and psychological health.

\section{Implications and Future Directions}

Research describing childrearing environments as "good enough" (Hoghughi \& Speight, 1998; Ryan, Martin, \& Brooks-Gunn, 2006; Winnicott, 1957), “average" (Baumrind, 1993), and even "positive" (von Suchodoletz, Trommsdorff, \& Heikamp, 2011), or that documents the resilience of children growing up in dangerous, abusive, neglectful, or otherwise compromised environments, is not the same as research focusing on child wellbeing. Substandard environments are relatively easy to identify based on the presence of factors that clearly undermine, if not threaten, children's development. Adequate parenting, although less well defined, was once centered on caregiving that was neither overtly problematic nor provided by someone with a clear psychiatric illness - rather low standards (Winnicott, 1957). More recent variations have raised the bar, including components like clear limits, unconditional love, and secure base provision (Hoghughi \& Speight, 1998), and sometimes caregivers with a background in child development, good mental health, and a commitment to parenting (Mrazek, 2013). Child wellbeing might have a higher bar yet.

Moving the goal of child wellbeing toward developmental optimization has promise for improving the lives of children (Amerijckx \& Humblet, 2014). Whereas a focus on eliminating serious compromises to development such as abuse, neglect, and poverty is critical, true wellbeing refers not just to the eradication of threats to physical and psychological health, but to practices and developmental contexts that allow children to flourish, reach their full potential, and engage with others in flexible and imaginative ways. As such, wellbeing will be fostered not just within the individual, but within the family and community as well. The research reviewed above suggests that closer adherence to EDN practices might provide a context that will facilitate the development of the psychological and physiological systems that maximize child wellbeing. Of course, our work has limitations; for example, it is limited to early childhood, largely crosssectional, a lot of it relies on maternal or retrospective reports, and it primarily focuses on samples from the US. These issues could be usefully addressed in future research. In particular, the relationship between EDN-consistent care and cultural variations in parenting needs further exploration.

Although our research has examined EDN-consistent care primarily within the context of the mother-child dyad, our findings have implications for the care of young children generally. In a world where many parents work outside the home, stellar child care becomes a critical component of wellbeing. As such, child care and early education programs might be evaluated based on the extent to which they adhere to EDN-consistent care. Such a process was undertaken by Kurth and Narvaez (2018), who evaluated and compared different approaches to early child care predominant in the USA in order to assess their provision of EDN-consistent care. The approaches included (1) Developmentally Appropriate Practice (National Association for the Education of Young Children, 2009); (2) the Child Wellbeing Framework (McMullen \& McCormick, 2016); (3) Resources for Infant Educarers (RIE; Gerber, 1998, with additional material 
cited from Carlisle Solomon 2013; Lansbury 2014); (4) Montessori (Montessori, 1966); and (5) Reggio Emilia (Edwards, Gandini, \& Forman 2012). Each program was assessed according to how much they supported aspects of the EDN: breastfeeding, responsiveness, positive touch, multiple familiar adult caregivers and free play. They were also compared on the extent to which they emphasized a positive climate, provided social and emotional support, and fostered selfregulation, sympathy, and compassion. Although all approaches emphasized child wellbeing in their own ways, Reggio Emilia was the most comprehensive in providing EDN-consistent care, followed by RIE and Montessori. These variations suggest that further investigation into the developmental trajectories of children whose experiences both in and outside the home might illuminate the significance of EDN-consistent care to children's outcomes, particularly those related to socioemotional development and sociomoral orientation.

Preliminary evidence also suggests that early EDN-consistent care might support healthy psychological and moral functioning in adolescence and adulthood. For example, a few adult studies of retrospective reports of EDN-related childhood experiences have found correlations with adult mental health and morality (Narvaez, 2018; Narvaez et al., 2016). Although again, an absence of psychopathology is not equivalent with wellbeing, the connections found are in the right direction, and the tie between EDN-consistent care and adult morality supports the idea that early experiences coordinate health, sociomoral engagement, and the formation of ideology, as has been suggested by others (e.g., Tomkins, 1965). The physiological, emotional and behavioral regulation development that the EDN supports might also contribute to the goal regulation that is evident in adolescent and adult moral flourishing (Bundick, Yeager, King, \& Damon, 2010). However, future work will need to consider the myriad developmental trajectories that lead from early childhood to adulthood; idiosyncratic variations within culture or as a function of disabilities might have implications for the role of EDN-consistent care in moral development.

\section{Conclusion}

Amerijckx and Humblet (2014) advocated a more positive, multi-dimensional approach to child wellbeing, a recommendation that we endeavor to follow in our work. As Baumrind (1993) pointed out, the absence of disadvantage in a caregiving environment is not equivalent to a developmental context of thriving. The wellbeing of children might be supported by raising the standards to include and facilitate EDN-consistent care. These practices seem to foster an engagement with others that might facilitate not just healthy interpersonal relations, but support for community. Such a focus is the basis for a mature moral ideology centered on the public good.

Widespread education is needed to increase understanding of children's basic needs and EDN provision, as part of basic human rights. Recently, advocates have been emphasizing the first 1000 days of life (from conception to the end of the second year) as the most important time period for establishing foundations and trajectories for good health and overall wellbeing (Schwarzenberg, Georgieff, \& AAP Committee on Nutrition, 2018). Based on the research reviewed here, the 1000 days emphasis on nutrition is a good start, but addressing and fulfilling the EDN might be central to promoting wellbeing in infants and young children. 


\author{
Authors \\ Tracy R. Gleason \\ Wellesley College \\ tgleason@wellesley.edu \\ Darcia Narvaez \\ University of Notre Dame

\section{Publishing Timeline} \\ Received 14 May 2019 \\ Accepted 23 September 2019 \\ Published 26 September 2019
}

\title{
References
}

Amato, P. (2005). The impact of family formation change on the cognitive, social, and emotional wellbeing of the next generation. The Future of Children, 15, 75-96.

Amerijckx, G., \& Humblet, P. C. (2014), Child wellbeing: What does it mean? Children E Society, 28, 404415. doi: $10.1111 /$ chso.12003

Baumrind, D. (1993). The average expectable environment is not good enough: A response to Scarr. Child Development, 64(5), 1299-1317. doi:10.2307/1131536

Bundick, M. J., Yeager, D. S., King, P. E., \& Damon, W. (2010). Thriving across the life span. In W. F. Overton, \& R. M. Lerner (Eds.), The Handbook of Life-Span Development, Vol. 1. Cognition, biology, and methods (pp. 882-923). Hoboken, NJ: Wiley.

Calkins, S. D. \& Fox, N. A. (1992). The relations among infant temperament, security of attachment, and behavioral inhibition at twenty-four months. Child Development, 63, 1456-1472.

Calkins, S. D., \& Hill, A. (2007). Caregiver influences on emerging emotion regulation: Biological and environmental transactions in early development. In J. J. Gross (Ed.), Handbook of Emotion Regulation (pp. 229-248). New York: Guilford Press.

Carlisle Solomon, D. (2013). Baby knows best: Raising a confident and resourceful child, the RIE way. New York: Little, Brown.

Carter, C. S., \& Porges, S. W. (2013). Neurobiology and the evolution of mammalian social behavior. In D. Narvaez, J. Panksepp, A. Schore \& T. Gleason (Eds.), Evolution, early experience and human development: From research to practice and policy (pp. 132-151). New York: Oxford.

Cemore, J. J., \& Herwig, J. E. (2005). Delay of gratification and make-believe play of preschoolers. Journal of Research in Childhood Education, 19(3), 251-266.

Doyle, A.-B., \& Connolly, J. (1989). Negotiation and enactment in social pretend play: Relations to social acceptance and social cognition. Early Childhood Research Quarterly, 4(3), 289-302. doi:10.1016/0885-2006(89)90015-X

Edwards, C., Gandini, L., \& Forman, G. (2012). Introduction: Background and starting points. In C. Edwards, L. Gandini, \& G. Forman (eds.), The hundred languages of children: The Reggio Emilia experiences in transformation, $3^{\text {rd }}$ ed. (pp. 5-26). New York, NY: Praeger.

Evans, C. A., \& Porter, C. L. (2009). The emergence of mother-infant co-regulation during the first year: Links to infants' developmental status and attachment. Infant Behavior E Development, 32(2), 147158. doi:10.1016/j.infbeh.2008.12.005 
Feldman, R., Gordon, I., \& Zagoory-Sharon, O. (2011). Maternal and paternal plasma, salivary, and urinary oxytocin and parent-infant synchrony: Considering stress and affiliation components of human bonding. Developmental Science, 14(4), 752-761.

Feldman, R., Greenbaum, C. W., \& Yirmiya, N. (1999). Mother-infant affect synchrony as an antecedent of the emergence of self-control. Developmental Psychology, 35(1), 223-231. doi:10.1037/00121649.35.1.223

Feldman, R., Weller, A., Sirota, L., \& Eidelman, A. I. (2002). Skin-to-skin contact (kangaroo care) promotes self-regulation in premature infants: Sleep-wake cyclicity, arousal modulation, and sustained exploration. Developmental Psychology, 38(2), 194-207. doi:10.1037/0012-1649.38.2.194

Field, T., Diego, M., \& Hernandez-Reif, M. (2010). Preterm infant massage therapy research: A review. Infant Behavior and Development, 33, 115-124.

Flanders, J. L., Herman, K. N., \& Paquette, D. (2013). Rough-and-tumble play and the cooperationcompetition dilemma: Evolutionary and developmental perspectives on the development of social competence. In D. Narvaez, J. Panksepp, A. Schore, \& T. Gleason, Evolution, early experience and human development: From research to practice and policy (pp. 371-387). New York: Oxford.

Fogel, A. (1993). Developing through relationships: Origins of communication, self and culture. Chicago: University of Chicago Press.

Fogel, A. (2000). Developmental pathways in close relationships. Child Development, 71(5), 1150-1151. doi:10.1111/1467-8624.00217

Fogel, A., \& Branco, A. (1997). Metacommunication as a source of indeterminism in relationship development. In A. Fogel, M. P. Lyra, \& J. Valsiner (Eds.), Dynamics and indeterminism in developmental and social processes (pp. 65-92). Hillsdale: Erlbaum.

Fredrickson, B. L., \& Losada, M. F. (2005). Positive affect and the complex dynamics of human flourishing. American Psychologist, 60, 678-686.

Gerber, M. (1998). Your self-confident baby: How to encourage your child's natural abilities-from the very start. New York: Wiley.

Gleason, T., \& Narvaez, D. (2014). Child environments and flourishing. In D. Narvaez, K. Valentino, A., Fuentes, J., McKenna, \& P. Gray (Eds.), Ancestral landscapes in human evolution: Culture, childrearing and social wellbeing (pp. 335-348). New York: Oxford.

Gleason, T., Narvaez, D., Cheng, A., Wang, L., \& Brooks, J. (2016). Wellbeing and sociomoral development in preschoolers: The role of maternal parenting attitudes consistent with the Evolved Developmental Niche. In D. Narvaez, J. Braungart-Rieker, L. Miller, L. Gettler, \& P. Hastings (Eds.), Contexts for young child flourishing: Evolution, family and society (166-184). New York: Oxford.

Gleason, T., Tarsha, M., Woodbury, R., Kurth, A., Kaikhosroshvili, K., \& Narvaez, D. (2019). Play, sociomoral development, and well-being. Manuscript in preparation.

Goldberg, E. (2002). The executive brain: Frontal lobes and the civilized brain. New York: Oxford.

Gray, P. (2013). The value of a play-filled childhood in development of the hunter-gatherer individual. In D. Narvaez, J. Panksepp, A. Schore, \& T. Gleason (Eds.), Evolution, early experience and human development: From research to practice and policy (pp. 362-370). New York: Oxford.

Gray, P. (2014). The play theory of hunter-gatherer egalitarianism. In D. Narvaez, K. Valentino, A. Fuentes, J. McKenna, \& P. Gray, (Eds.) Ancestral landscapes in human evolution: Culture, childrearing and social wellbeing (pp. 190-213). New York: Oxford.

Gunnar, M. R., Larson, M. C., Hertsgaard, L., Harris, M. L., \& Broderson, L. (1992). The stressfulness of separation among nine-month-old infants: Effects of social context variables and infant temperament. Child Development, 63(2), 290-303. doi:10.2307/1131479 
Harlow, H. (1986). From learning to love. New York: Praeger.

Hewlett, B. S., \& Lamb, M. E. (2005). Hunter-gatherer childhoods: Evolutionary, developmental and cultural perspectives. New Brunswick, NJ: Aldine Transaction.

Hoffman, M. L. (1970). Moral development. In P. H. Mussen (Ed.), Carmichael's manual of child development (Vol. 2, pp. 261- 359). New York: Wiley.

Hoghughi, M., \& Speight, A. N. P. (1998). Good enough parenting for all children - a strategy for a healthier society. Archives of Disease in Childhood, 78(4), 293-296.

Holden, G., \& Buck, M. J. (2002). Parental attitudes toward childrearing. In M. Bornstein (Ed.), Handbook of parenting (2nd ed.), Vol. 3: Being and becoming a parent (pp. 537-562). Mahwah, NJ: Erlbaum.

Howe, N., Petrakos, H., \& Rinaldi, C. M. (1998). 'All the sheeps are dead. He murdered them': Sibling pretense, negotiation, internal state language, and relationship quality. Child Development, 69(1), 182-191. doi:10.2307/1132079

Hrdy, S. (2009). Mothers and others: The evolutionary origins of mutual understanding. Cambridge, MA: Belknap Press.

Karrass, J., \& Walden, T. A. (2005). Effects of nurturing and non-nurturing caregiving on child social initiatives: An experimental investigation of emotion as a mediator of social behavior. Social Development, 14(4), 685-700. doi:10.1111/j.1467-9507.2005.00324.x

Kochanska, G. (2002). Mutually responsive orientation between mothers and their young children: A context for the early development of conscience. Current Directions in Psychological Science, 11, 191-195.

Konner, M. (2005). Hunter-gatherer infancy and childhood: The !Kung and others. In B. Hewlett \& M. Lamb (Eds.), Hunter-gatherer childhoods: Evolutionary, developmental and cultural perspectives (pp. 19-64). New Brunswick, NJ: Aldine Transaction.

Koverola, C., Papas, M. A., Pitts, S., Murtaugh, C., Black, M. M., \& Dubowitz, H. (2005). Longitudinal investigation of the relationship among maternal victimization, depressive symptoms, social support, and children's behavior and development. Journal of Interpersonal Violence, 20(12), 15231546. doi:10.1177/0886260505280339

Kruger, A. (1992). The effect of peer and adult-child transductive discussions on moral reasoning. MerrillPalmer Quarterly, 38, 191-211.

Kurth, A., \& Narvaez, D. (2018). Children's developing morality. In J. Delafield-Butt, A-W. Dunlop \& C. Trevarthen (Eds.), The child's curriculum: Working with the natural values of young children (pp. 104125). Oxford: Oxford University Press.

Lancy, D. F. (2015). The anthropology of childhood: Cherubs, chattel, changelings, 2nd Ed. New York: Cambridge.

Lanius, R. A., Vermetten, E., \& Pain, C. (2010). The impact of early life trauma on health and disease: The hidden epidemic. New York: Cambridge.

Lansbury, J. (2014). Elevating child care: A guide to respectful parenting. Online: JLML Press. independently published and printed by CreateSpace.

Lillard, A. S., Lerner, M. D., Hopkins, E. J., Dore, R. A., Smith, E. D., \& Palmquist, C. M. (2013). The impact of pretend play on children's development: A review of the evidence. Psychological Bulletin, 139(1), 1-34. doi:10.1037/a0029321

Lindsey, E. W., \& Colwell, M. J. (2013). Pretend and physical play: Links to preschoolers' affective social competence. Merrill-Palmer Quarterly, 59(3), 330-360.

Lupien, S. J., McEwen, B. S., Gunnar, M. R., \& Heim, C. (2009). Effects of stress throughout the lifespan on the brain, behaviour and cognition. Nature Reviews Neuroscience, 10(6), 434-445. 
McConnell, D., Breitkreuz, R., \& Savage, A. (2011). From financial hardship to child difficulties: Main and moderating effects of perceived social support. Child: Care, Health and Development, 37(5), 679-691. doi:10.1111/j.1365-2214.2010.01185.x

McKenna, J., Mosko, S., Richard, C., Drummond, S., Hunt, L., Cetel, M. B., \& Arpaia, J. (1994). Experimental studies of infant-parent co-sleeping: Mutual physiology and behavioral influences and their relevance to SIDS (sudden infant death syndrome). Early Human Development, 38(3), 187-201. doi:10.1016/0378-3782(94)90211-9

McMullen, M. B., \& McCormick, K. (2016). Flourishing in transactional care systems: Caring with infant and toddler caregivers about wellbeing. In D. Narvaez, J. Braungart-Rieker, L. Miller, L. Gettler, \& P. Hastings (Eds.), Contexts for young child flourishing: evolution, family and society (pp. 267-287). New York: Oxford.

Masten, A. S., Best, K. M., \& Garmezy, N. (1990). Resilience and development: Contributions from the study of children who overcome adversity. Development and Psychopathology, 2(4), 425-444. doi:10.1017/S0954579400005812

Meaney, M. J. (2001). Maternal care, gene expression, and the transmission of individual differences in stress reactivity across generations. Annual Review of Neuroscience, 24, 1161-1192.

Montagu, A. (1968). Brains, genes, culture, immaturity, and gestation. In A. Montagu (Ed.), Culture: Man's adaptive dimension (pp. 102-113). New York: Oxford.

Montessori, M. (1966). The secret of childhood. New York: Ballantine Books, Inc.

Moore, G. A., Hill-Soderlund, A. L., Propper, C. B., Calkins, S. D., Mills-Koonce, W. R., \& Cox, M. J. (2009). Mother-infant vagal regulation in the face-to-face still-face paradigm is moderated by maternal sensitivity. Child Development, 80, 209-223.

Morelli, G., Ivey Henry, P., \& Foerster, S. (2014). Relationships and resource uncertainty: Cooperative development of Efe hunter-gatherer infants and toddlers. In D. Narvaez, K. Valentino, A. Fuentes, J. McKenna, \& P. Gray, Ancestral landscapes in human evolution: Culture, childrearing and social wellbeing (pp. 69-103). New York: Oxford.

Mrazek, D. A. (2013). Caregiving in early childhood. In R. C. Talley \& R. J. V. Montgomery (Eds.), Caregiving across the lifespan: Research, practice, policy. (pp. 11-20). New York: Springer Science + Business Media.

Narvaez, D. (2008). Triune ethics: The neurobiological roots of our multiple moralities. New Ideas in Psychology, 26, 95-119. doi:10.1016/j.newideapsych.2007.07.008

Narvaez, D. (2014). Neurobiology and the development of human morality: Evolution, culture and wisdom. New York: Norton.

Narvaez, D. (Ed.) (2018). Basic needs, wellbeing and morality: Fulfilling human potential. New York: Palgrave-MacMillan.

Narvaez, D., Gleason, T., Wang, L., Brooks, J., Lefever, J., Cheng, A., \& Centers for the Prevention of Child Neglect (2013). The Evolved Development Niche: Longitudinal effects of caregiving practices on early childhood psychosocial development. Early Childhood Research Quarterly, 28 (4), 759-773. doi: 10.1016/j.ecresq.2013.07.003

Narvaez, D., Panksepp, J., Schore, A., \& Gleason, T. (2013). Evolution, early experience and human development: From research to practice and policy. New York: Oxford.

Narvaez, D., Wang, L, \& Cheng, A. (2016). Evolved Developmental Niche History: Relation to adult psychopathology and morality. Applied Developmental Science, 20(4), 294-309. doi: 10.1080/10888691.2015.1128835 
Narvaez, D., Wang, L., Cheng, A., Gleason, T. R., Woodbury, R., Kurth, A., \& Lefever, J. B. (2019). The importance of early life touch for psychosocial and moral development. Psicologia: Reflexão e Crítica, 32(1), 16. doi:10.1186/s41155-019-0129-0

Narvaez, D., Wang, L., Gleason, T., Cheng, A., Lefever, J., \& Deng, L. (2013). The Evolved Developmental Niche and sociomoral outcomes in Chinese three-year-olds. European Journal of Developmental Psychology, 10(2), 106-127.

Narvaez, D., Woodbury, R., Gleason, T., Kurth, A., Cheng, A., Wang, L., Deng, L., GutzwillerHelfenfinger, E., Christen, M., \& Näpflin, C. (2019). Evolved Development Niche Provision: Moral socialization, social maladaptation and social thriving in three countries. Sage Open, 9(2). doi:10.1177/2158244019840123

National Association for the Education of Young Children. (2009). Developmentally appropriate practice in early childhood programs serving children from birth through age 8. Retreived from https://www.naeyc.org/positionstatements/dap

Oyama, S. (1985). The ontogeny of information: Developmental systems and evolution. Cambridge: Cambridge University Press.

Oyama, S., Griffiths, P.E., \& Gray, R.D. (2001). Cycles of contingency: Developmental systems and evolution. Cambridge, MA: MIT Press.

Pellegrini, A. D. \& Pellegrini A. F. A. (2013). Play, plasticity, and ontogeny in childhood. In D. Narvaez, J. Panksepp, A. Schore, \& T. Gleason, Evolution, early experience and human development: From research to practice and policy (pp. 339-351). New York: Oxford.

Pellegrini, A. D., \& Smith, P. K. (1998). The development of play during childhood: Forms and possible functions. Child Psychology \& Psychiatry Review, 3(2), 51-57. doi:10.1017/S1360641798001476

Posner, M. I., \& Rothbart, M. K. (1998). Attention, self-regulation and consciousness. Philosophical Transactions of the Royal Society of London, Series B, Biological Sciences, 353(1377), 1915-1927.

Ryan, R. M., Martin, A., \& Brooks-Gunn, J. (2006). Is one good parent good enough? Patterns of mother and father parenting and child cognitive outcomes at 24 and 36 months. Parenting: Science and Practice, 6(2-3), 211-228. doi:10.1207/s15327922par0602\&3_5

Sanders, S. R. (2009). A conservationist manifesto. Bloomington, IN: Indiana University Press.

Sapolsky, R. M. (2004). Why zebras don't get ulcers (3rd ed.). New York: Holt.

Schore, A. (2003a). Affect regulation and the repair of the self. New York: Norton.

Schore, A. (2003b). Affect dysregulation and disorders of the self. New York: Norton.

Schore, A. (2013). Bowlby's "Environment of evolutionary adaptedness": Recent studies on the interpersonal neurobiology of attachment and emotional development. In D. Narvaez, J. Panksepp, A. Schore \& T. Gleason (Eds.), Evolution, early experience and human development: From research to practice and policy (pp. 31-67). New York: Oxford.

Schore, J., \& Schore, A. (2008). Modern attachment theory: The central role of affect regulation in development and treatment. Clinical Social Work Journal, 36, 9-20.

Schwarzenberg, S. J., Georgieff, M. K., \& AAP Committee on Nutrition (2018). Advocacy for improving nutrition in the first 1000 days to support childhood development and adult health. Pediatrics, 141(2), e20173716. doi:10.1542/peds.2017-3716

Spangler, G., Schieche, M., Ilg, U., Maier, U. \& Ackerman, C. (1994), Maternal sensitivity as an external organizer for biobehavioral regulation in infancy. Developmental Psychobiology, 27, 425-437.

Sroufe, L. (1996). Emotional development: The organization of emotional life in the early years. New York: Cambridge.

Thompson, R. A. (2011). Emotion and emotion regulation: Two sides of the developing coin. Emotion Review, 3, 53-61. 
Tomkins, S. (1965). Affect and the psychology of knowledge. In S. S. Tomkins \& C. E. Izard (Eds.), Affect, cognition, and personality. New York: Springer.

Trevathan, W. R. (2011). Human birth: An evolutionary perspective, 2nd Ed. New York: Aldine de Gruyter. Tronick, E. (2007). The neurobehavioral and social-emotional development of infants and children. New York: Norton.

Tucker, D. M., Derryberry, D., \& Luu, P. (2000). Anatomy and physiology of human emotion: Vertical integration of brainstem, limbic, and cortical systems. In J. C. Borod (Ed.), The neuropsychology of emotion (pp. 56-79). London: Oxford University Press.

von Suchodoletz, A., Trommsdorff, G., \& Heikamp, T. (2011). Linking maternal warmth and responsiveness to children's self-regulation. Social Development, 20(3), 486-503. doi:10.1111/j.14679507.2010.00588.x

Walker, L. J., Hennig, K. H., \& Krettenauer, T. (2000). Parent and peer contexts for children's moral reasoning development. Child Development, 71, 1033- 1048.

Winnicott, D. W. (1957). The child and the family. New York: Basic Books.

Woolf, A. (2011). Everyone Playing in Class: A group play provision for enhancing the emotional wellbeing of children in school. British Journal of Special Education, 38(4), 178-190. 